\title{
Perforación colónica como complicación tardía de un catéter de quimioterapia intraperitoneal
}

Colonic perforation as late complication of intraperitoenal chemotherapy catheter

Felipe Imigo G. ${ }^{1}$, Richard Castillo R. ${ }^{1}$, Mauricio Cuello F. ${ }^{2}$ y Felipe Bellolio R. ${ }^{1}$

'Unidad de Coloproctología, Departamento de Cirugía Digestiva. Pontificia Universidad Católica de Chile Santiago, Chile.

2División de Obstetricia

y Ginecología. Pontificia Universidad Católica de Chile, Santiago, Chile.

Recibido el 24 de ener de 2017 y aceptado para publicación el 7 de junio de

2017

Correspondencia a: Dr. Felipe Bellolio R. fbelloli@med.puc.c
Mujer de 68 años quien en el contexto de terapia adyuvante por cáncer de ovario etapa III recibió 4 ciclos de quimioterapia a través de un catéter intraperitoneal instalado vía laparoscópica. Posteriormente se obstruyó, completando los restantes ciclos por vía intravenosa.

Tres meses luego de finalizada la quimioterapia, asintomática, se realizó imagen de seguimiento con una tomografía computarizada de abdomen, no evidenciando signos de recidiva, sin embargo, se sospechó la presencia del extremo distal del catéter en situación intracolónica ingresando por el colon descendente (Figuras 1 y 2).

Se realizó colonoscopia donde se identificó a nivel del colon descendente la entrada del catéter, el cual se extendía por $15 \mathrm{~cm}$ hacia proximal (Figuras 3 y 4).

Se planificó el retiro en pabellón liberando el reservorio del tejido subcutáneo y posteriormente traccionando el catéter sin encontrar resistencia. La paciente cursó un posoperatorio sin complicaciones, siendo dada de alta al segundo día.

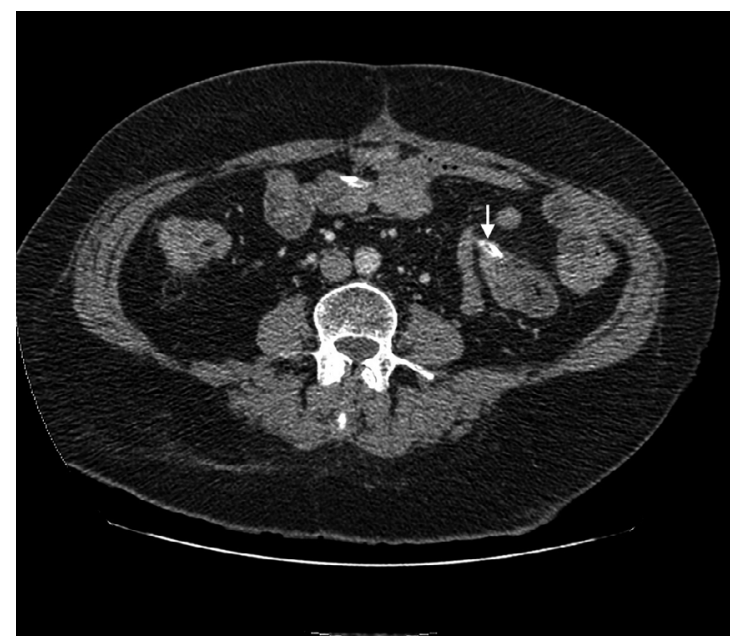

Figura 1. Tomografía de abdomen, corte axial. La flecha marca el sitio de inserción del catéter en colon descendente.

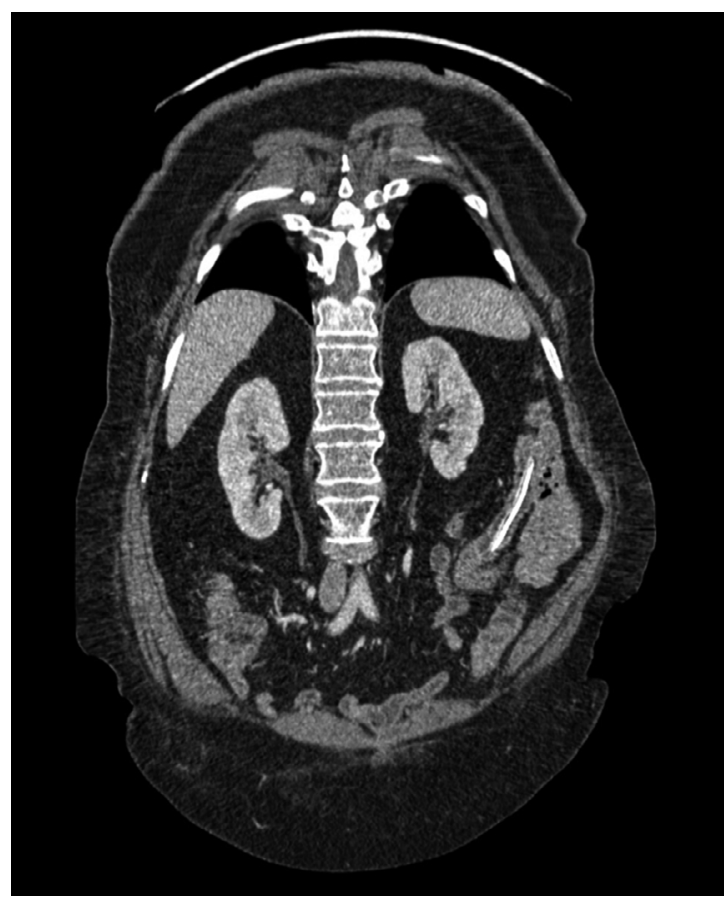

Figura 2. Tomografía de abdomen y pelvis, corte coronal. Se aprecia trayecto intraluminal en colon descendente del catéter.

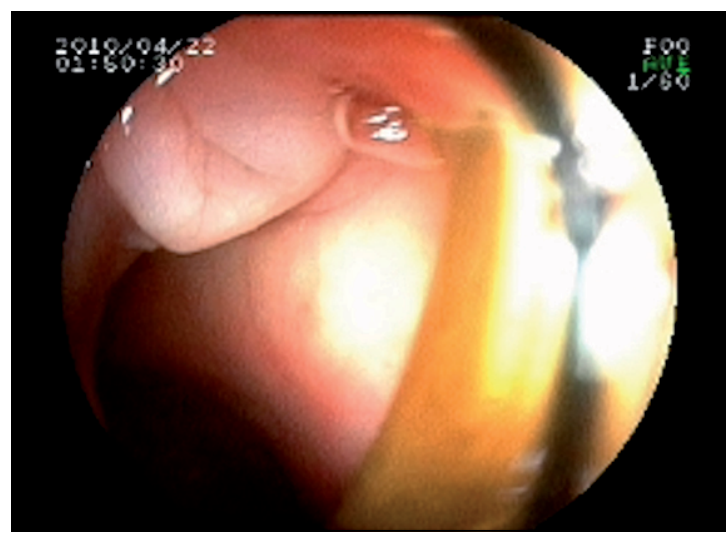

Figura 3. Colonoscopia. Se aprecia sitio de entrada del catéter a la luz. 


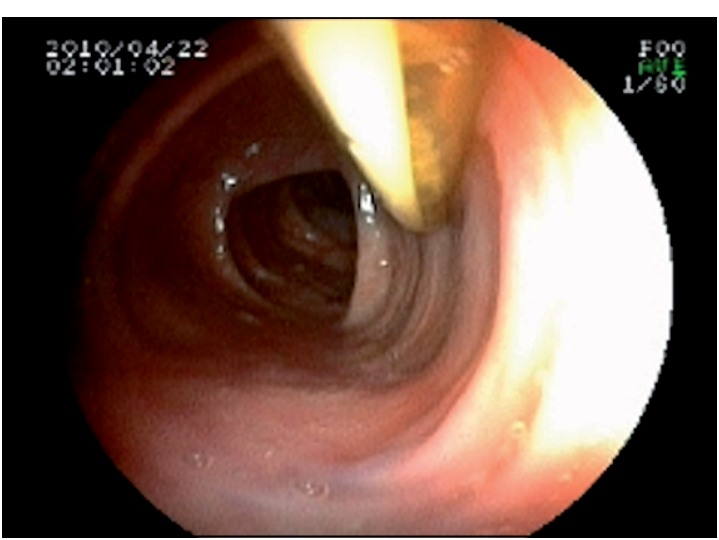

Figura 4. Colonoscopia. Trayecto intraluminal del catéter.

Las complicaciones asociadas al catéter intraperitoneal se presentan en el $10 \%$ de los pacientes. Las más frecuentes son la disfunción por obstrucción luminal y las complicaciones infecciosas intraperitoneales o de la piel. La complicación colónica más frecuente es la perforación al momento de la inserción. La perforación colónica tardía es una complicación infrecuente ${ }^{1-3}$.

\section{Responsabilidades éticas}

Protección de personas y animales. Los autores declaran que para esta investigación no se han realizado experimentos en seres humanos ni en animales.

Confidencialidad de los datos. Los autores declaran que en este artículo no aparecen datos de pacientes.

Derecho a la privacidad y consentimiento informado. Los autores declaran que en este artículo no aparecen datos de pacientes.

\section{Financiación}

Los autores declaran no haber recibido ninguna financiación para la realización de este trabajo.

\section{Conflicto de intereses}

Los autores declaran no tener ningún conflicto de intereses.

\section{Bibliografía}

1. Kinoshita J, Fushida S, Tsukada T, Oyama K, Watanabe T, Okamoto K, et al. Colonic stenosis caused by infection of an intraperitoneal access port system: A rare complication of intraperitoneal che- motherapy for gastric cancer with peritoneal metastasis. World J Surg Oncol. 2014;12:177.

2. Landrum L, Gold M, Moore K, Myers T, McMeekin D, Walker J. Intraperitoneal chemotherapy for patients with advanced epit- helial ovarian cancer: A review of complications and completion rates. Gynecol Oncol. 2008;108:342-7.

3. Makhija S, Leitao M, Sabbatini P, Bellin N, Almadrones L, Leon L, et al. Complications associated with intraperitoneal chemothe- rapy catheters. Gynecol Oncol. 2001;81:77-81. 